\title{
Low-Backlash Worm Gears with NiTi Shape Memory Alloys
}

\author{
W. Predki, B. Bauer ${ }^{\mathrm{a}, 1}$ \\ Ruhr-University Bochum, 44801 Bochum, Germany \\ ${ }^{1}$ Department of Mechanical Engineering, Ruhr-University Bochum, Germany
}

\begin{abstract}
This paper investigates the use of martensitic Nickel-Titanium within worm gear transmissions in order to reduce the backlash of the gearwheels. In drive technology low-backlash transmissions are demanded. The backlash, adjusted at room temperature, decreases with increasing temperature as a consequence of different thermal expansions of the gear wheels and the housing. This can result in clamping of the teeth and leads to failure of the whole transmission. With NiTi-actuators, working in the extrinsic two-way effect, it is possible to realize two conditions of low-backlash and to avoid clamping of the gear wheels. The actuators induce a radial movement of the worm wheel depending on the increasing temperature within the gearbox. The decreasing backlash, as a result of different thermal expansions, is compensated by the expansion of the martensitic NiTi actuators while transforming to the austenite. The adjustment travel of the actuators has to correspond to the thermal change of the centre distance. By measuring the change of backlash on the test bench, the theoretical dimensioning of the actuator system can be verified. The variation of the main parameters like torque, the speed and different temperature levels as a result of the input power should demonstrate the effectiveness of the NiTi actuators.
\end{abstract}

\section{INTRODUCTION}

The use of NiTi shape memory alloys as actuator material is based on high adjustment travel combined with high actuating forces. This makes NiTi attractive for the technical use within drive technology. Although the potential of this actuator material is very high, the use of NiTi SMA in the range of gear technology is not wide spread. Especially in automation technology, high precision for positioning problems is demanded. The fabrication quality for the different parts of a transmission has to be very high. Especially the backlash of the gear wheels is demanded to be small. Thermal expansions in the transmission lead to a decreasing backlash in the heating phase and may cause clamping of the gearwheels which is followed by the failure of the transmission. The use of NiTi actuators offers a solution for this problem, so that a low backlash can be realized over the range of operating temperature of the transmission.

\section{MATERIALS AND EFFECTS}

The variation of the backlash with NiTi-SMA is based on the extrinsic two-way effect with martensitic NiTielements at ambient temperature. The NiTi-actuators are clamped against steel springs in martensitic condition. The heating of the system leads to the transformation from martensite to austenite. The stiffness of the NiTielements increases and the compressed elements expand to reach their original shape [1]. A body that is clamped between the steel springs and the NiTi actuators would be moved in the direction of the NiTi-expansion during the microstructural transformation. Fig. 1 shows the schematic processes in the $\sigma-\varepsilon$-diagram.

The first step is the compression of the spring system. The compression of the NiTi-actuators occurs from point 0 to point 1 according to Fig. 1 . The working point 1 in the martensite is characterized by the stress $\sigma_{\text {Mart1 }}$ and the compression $\varepsilon_{\text {Mart }}$. An increasing temperature now leads to the transformation from martensite to austenite. Depending on the stiffness of the steel springs, that affect the slope of the connecting line between the $\sigma-\varepsilon$ runs of martensite and austenite, the stiffness of the NiTi-actuators increases. When the Austenite-FinishTemperature has exceeded, the austenitic working point 2 is reached. The adjustment travel of the clamped part is given by the difference between $\varepsilon_{\text {Mart } 1}$ and $\varepsilon_{\text {Aust2 }}$. In combination with the unloaded length $1_{0}$ of the actuators an

\footnotetext{
a e-mail: bjoern.bauererub.de
}

This is an Open Access article distributed under the terms of the Creative Commons Attribution-Noncommercial License (http://creativecommons.org/licenses/by-nc/3.0/), which permits unrestricted use, distribution, and reproduction in any noncommercial medium, provided the original work is properly cited. 
adjustment travel can be calculated. During the cooling phase after reaching the Martensite-Start-Temperature $\mathrm{M}_{\mathrm{s}}$ the stiffness of the actuators decreases and the steel springs cause a new compression of the NiTi-actuators. The working point 1 is reached again after cooling below the Martensite-Finish-Temperature $\mathrm{M}_{\mathrm{f}}$.

\section{Stress o}

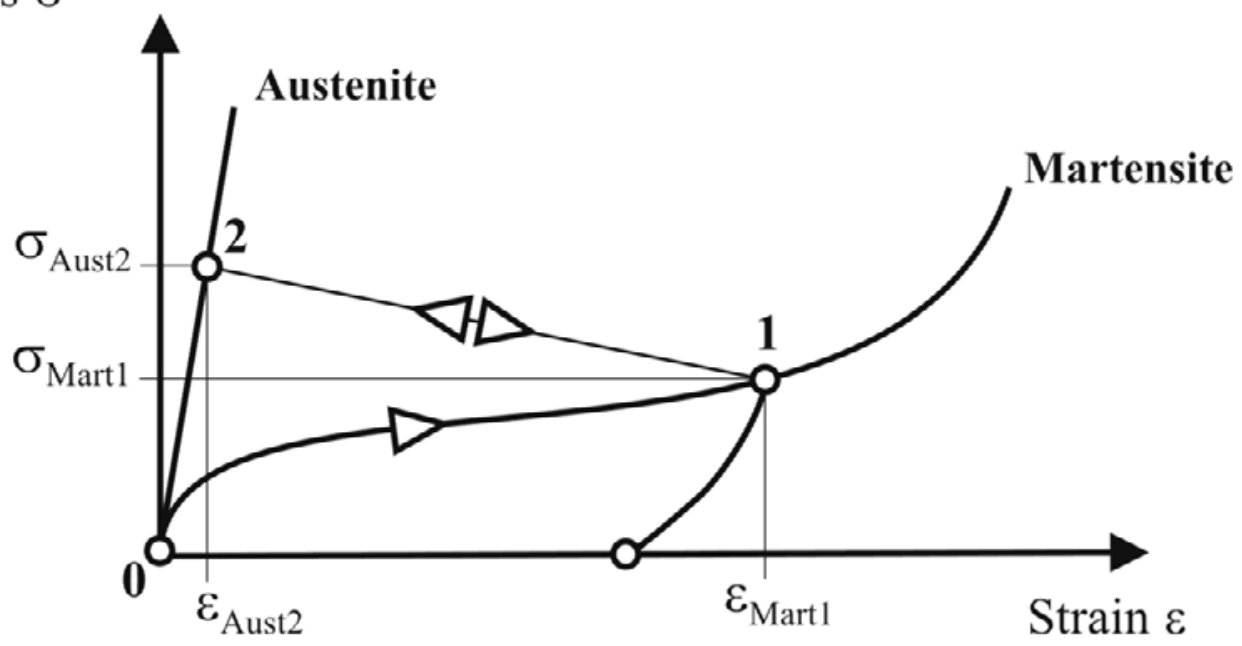

Fig. 1. Schematic process of the extrinsic two-way effect in the stress-strain diagram

In case of the applications within transmissions, the actuator system is influenced by external forces. In this case these forces are the bearing reaction as a result of the gear forces. Regarding the effective direction the bearing forces lead to an unloading of the NiTi-actuators. The effect is shown in Fig. 2 regarding the stress-compression behavior.

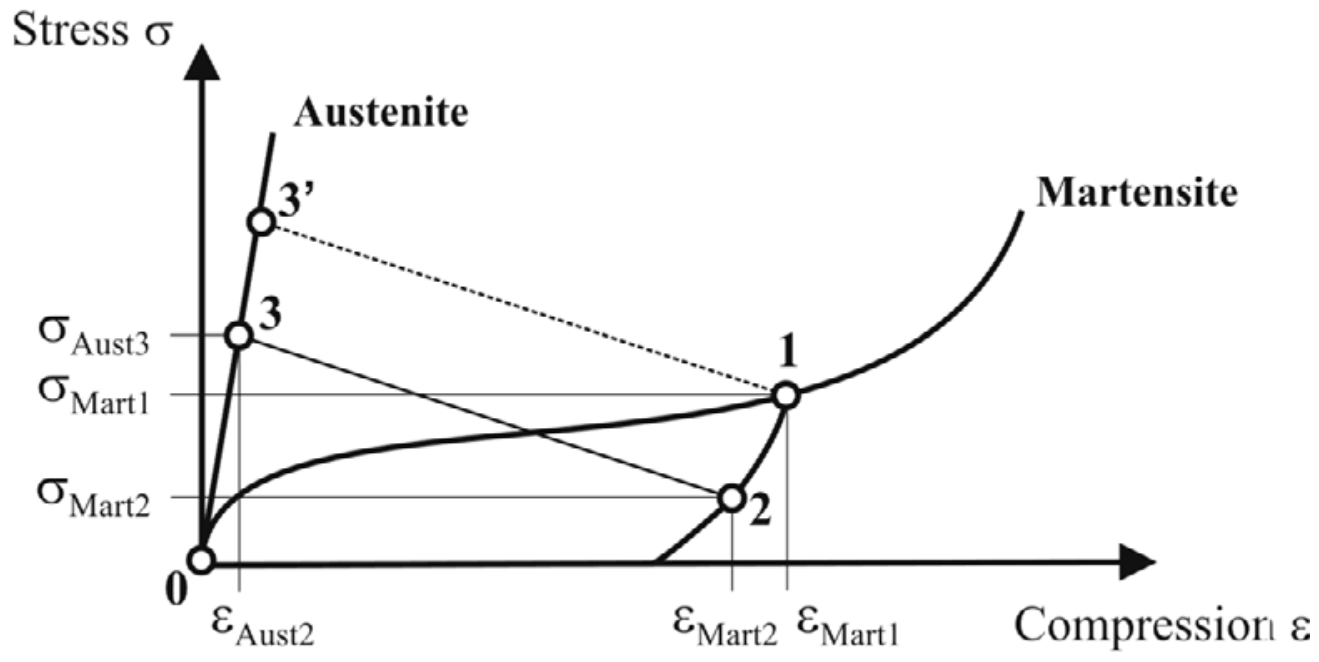

Fig. 2. Schematic process of the extrinsic two-way effect in the stress-compression diagram

After compressing the NiTi-elements (0-1) the actuator system is mounted in the transmission. The torque causes the gear forces that lead to bearing reactions. The radial force on the side of the clamped bearing sleeve leads to an unloading of the NiTi-elements and to an additional loading of the steel springs. The unloading path of the NiTi-elements in martensitic condition is shown in Fig. 2 (1-2). Depending on the value of the bearing reaction the working point 2 lies between the working point 1 and the stress level $\sigma=0$ in case of complete unloading. The working point in the austenite changes from point 3 ' in case of no external force to point 3. 


\section{DESIGN OF THE WORM GEAR AND MEASURING}

To verify the theoretical considerations a test gear is designed. The conceptual design is shown in Fig. 3.

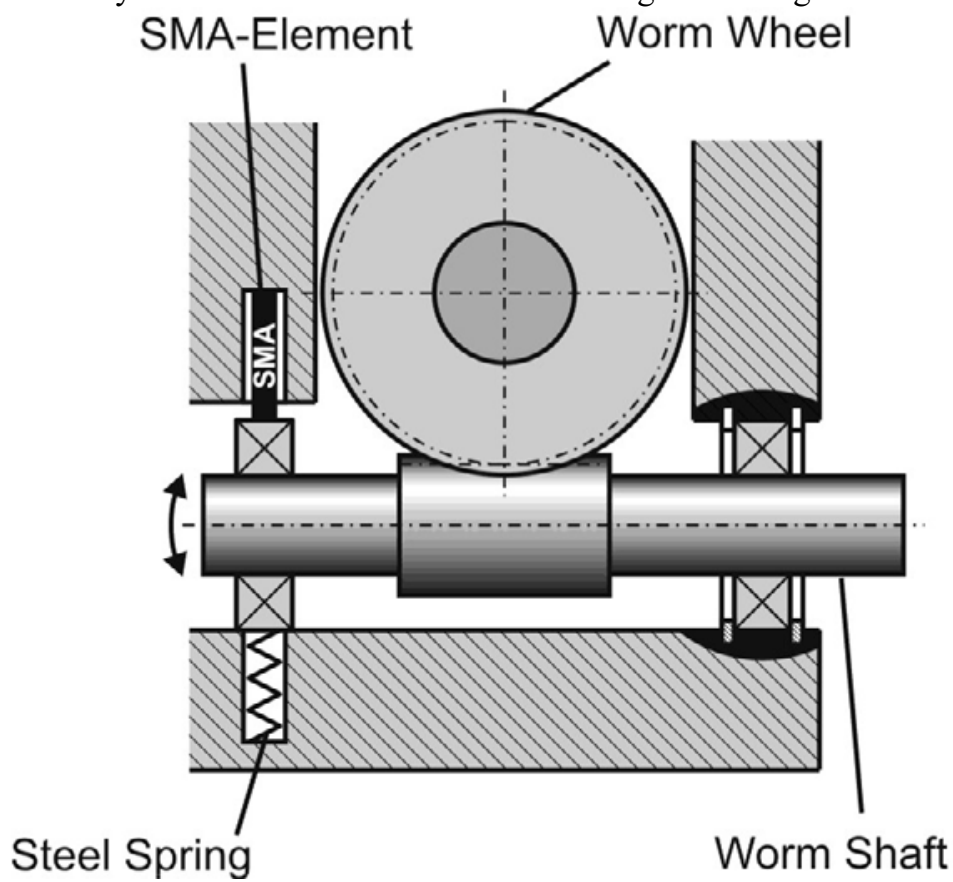

Fig. 3. Conceptual design of the worm gear with variable backlash adjustment by NiTi-actuator system

The left bearing of the worm gear shaft is clamped between the NiTi-actuators on the top and steel springs on the bottom side. The backlash of the gearwheels in cold condition takes very low values. An increasing temperature leads to a change of the centre distance as a result of different thermal expansions of the gearwheels and the housing. In most cases, the temperature of the gearwheels is higher than the temperature of the housing. For similar coefficients of thermal expansion, the centre distance and the backlash decrease. The clamping of the gearwheels could be the result of this effect. The different thermal expansions should be compensated with the NiTi-actuators. The transformation during the heating phase leads to an expansion of the compressed elements and the worm gear shaft is moved downwards. This leads to an increasing centre distance and backlash. During the cooling phase this adjustment travel is reversed by the steel springs that cause a new compression of the martensitic NiTi-actuators. The centre distance reaches its nominal value that was adjusted before the bench test.

Based on the concept shown in Fig. 3 the design of the worm gear is developed. Fig. 4 shows the testing transmission with the spring system on the left side and the pivotal point on the right side. The worm shaft (1) is mounted in a ball bearing (2) on the left side. This bearing is mounted in a bearing sleeve (3). The sleeve is clamped in vertical direction between the NiTi-actuators (4) on the top and the steel disc springs (5) on the bottom. The NiTi-actuator system consists of two cylindrical NiTi-rods with a diameter of $\mathrm{d} 0=2.8 \mathrm{~mm}$ and a total length of $10=6.0 \mathrm{~mm}$ in unloaded condition. The total cross sectional area of the actuators amounts to ANiTitotal $=12.32 \mathrm{~mm} 2$. The steel springs are standardized in DIN 2093 [2].

With the help of incremental encoders, the change of backlash can be measured. Each shaft is connected with one encoder. The encoder of the worm wheel starts the counter in a defined position. The counter counts the increments of the encoder connected to the worm gear shaft, which also gives the stop signal in another defined position. A change of backlash now leads to a relative movement of the start and the stop position of the two encoders. This leads to a change of the counted increments. In combination with the resolution of the counting encoder and the geometry of the gearwheels the change of backlash can be calculated $[3,4]$. 


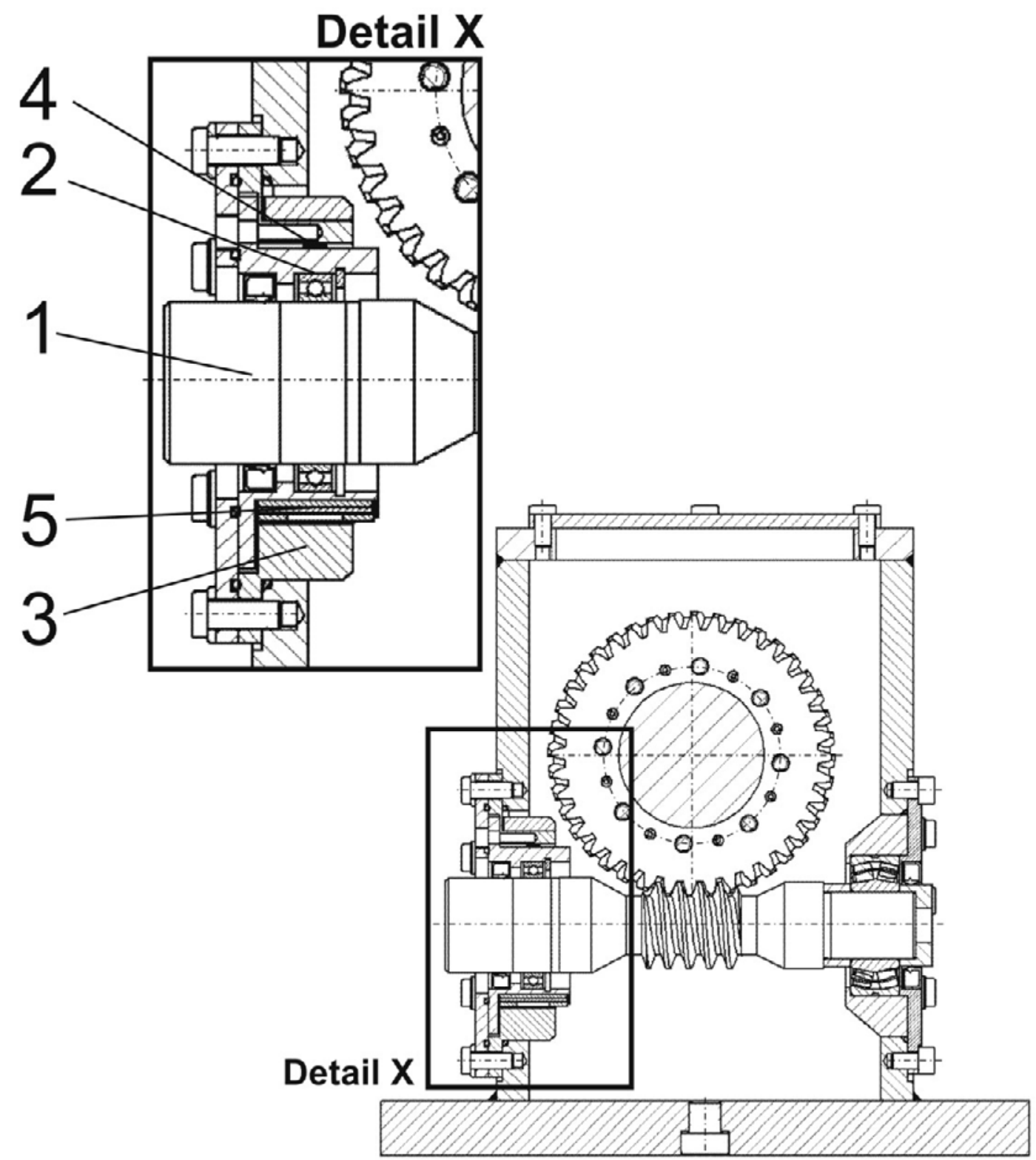

Fig. 4. Design of the test worm gear with a scaled up illustration of the actuator system

\section{MEASUREMENT RESULTS}

To prove the effectiveness of the actuator system and to analyze the influence of the different load parameters the transmission is tested in static and dynamic tests. The static tests occur in a climate chamber where the temperature is increased. The adjustment travel is measured with inductive distance sensors at the worm gear shaft. The measured adjustment travel at the position of the inductive distance sensor has to be converted into the adjustment travel of the SMA-elements and the change of the centre distance at the meshing. Fig. 5 shows the relationship.

Fig. 6 shows the change of the centre distance $\Delta$ a over the SMA-temperature for three different versions of the actuator system. 


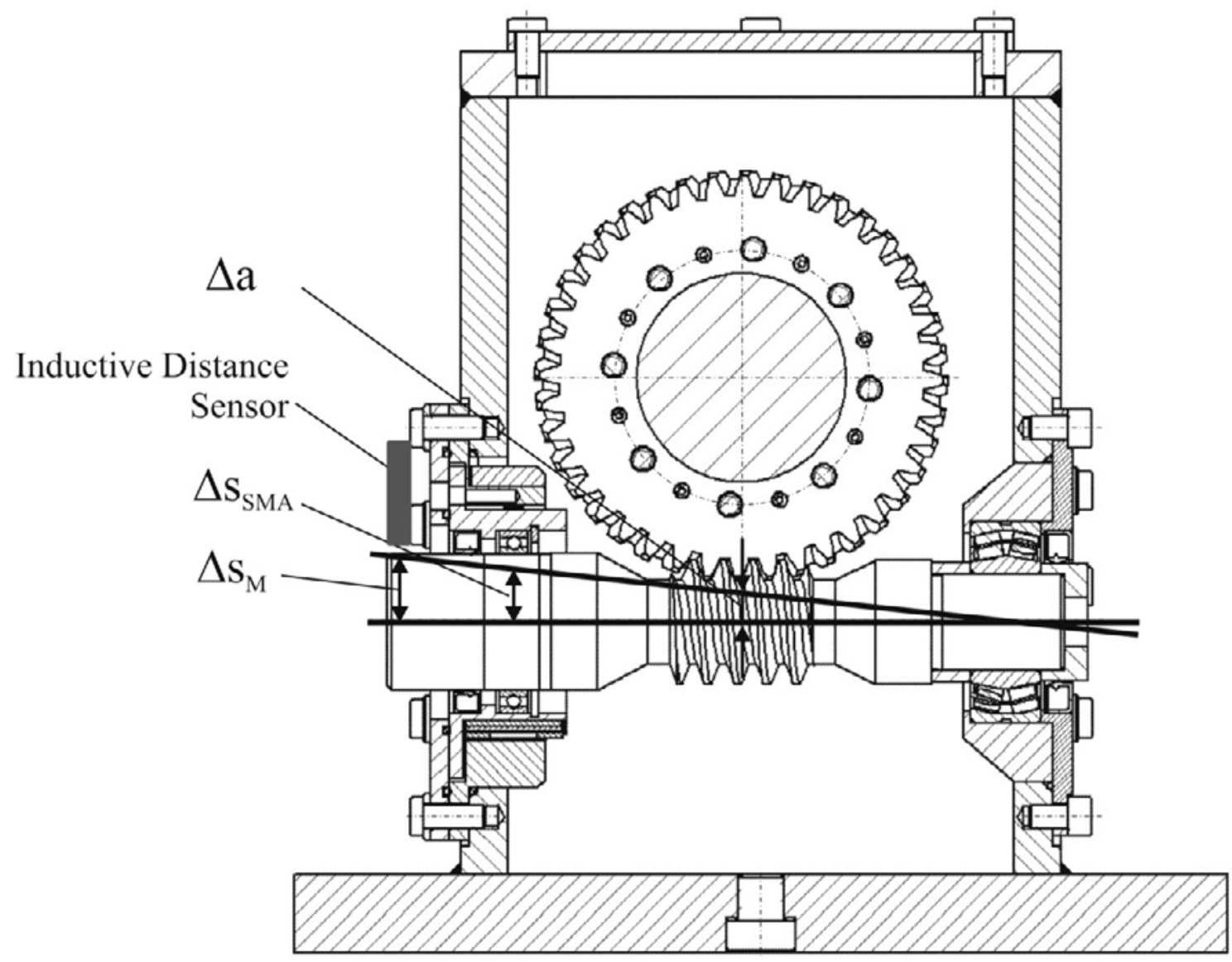

Fig. 5. Relationship between the measured adjustment travel $\Delta \mathrm{s}_{\mathrm{M}}$, the adjustment travel of the SMA-elements $\Delta \mathrm{s}_{\mathrm{SMA}}$ and the change of centre distance $\Delta \mathrm{a}$

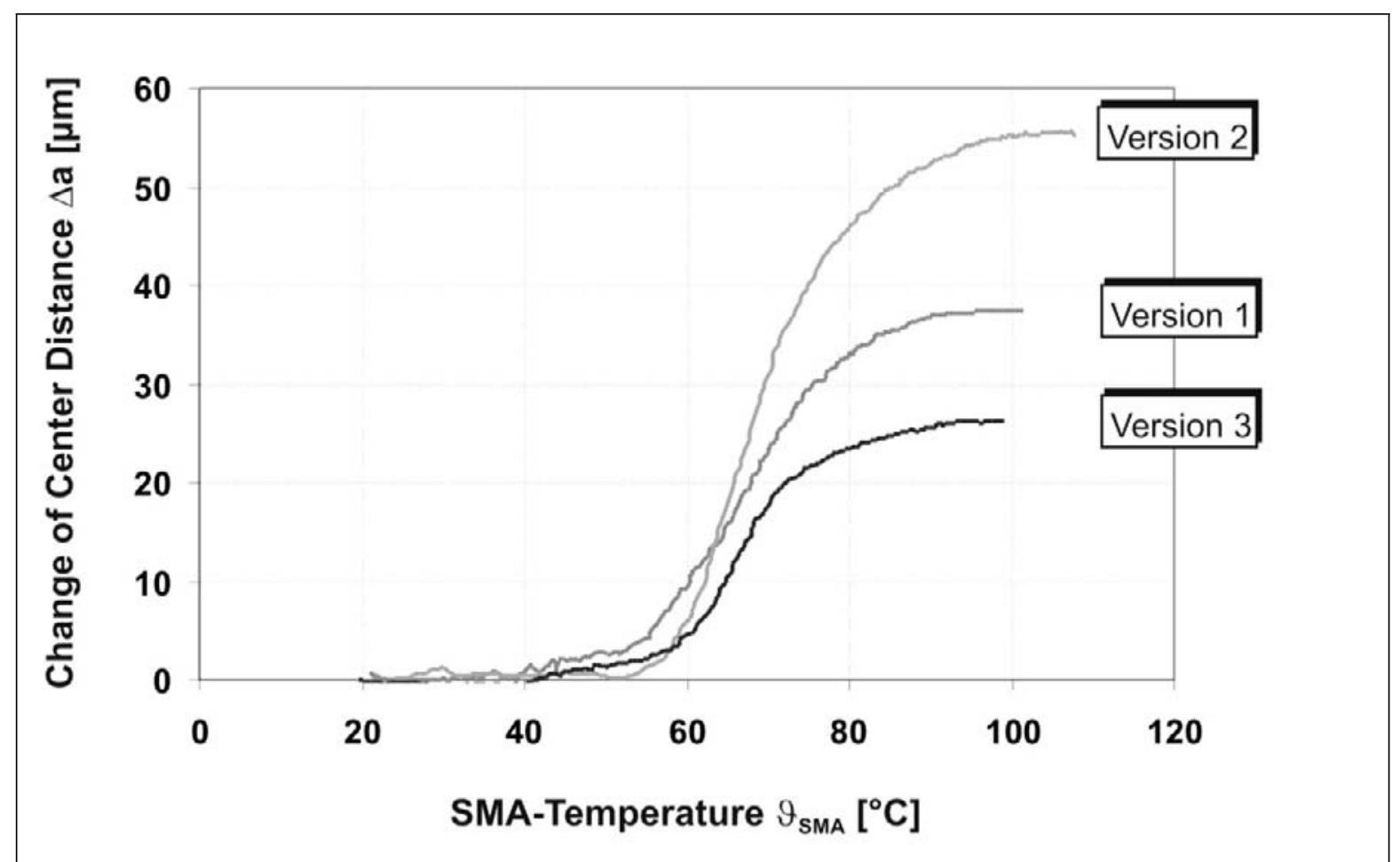

Fig. 6. Measurement results of the static tests in the climate chamber for three versions of the actuator system regarding the change of the centre distance over the SMA-temperature 
The difference between the three versions refers to the stiffness of the steel springs and the total compression $\mathrm{s}_{\text {tot }}$ of the spring system. This leads to different adjustment travels of the SMA-actuators and thus to different changes of the centre distance $\Delta \mathrm{a}$. The measured values amount $38 \mu \mathrm{m}$ for version $1,56 \mu \mathrm{m}$ for version 2 and $27 \mu \mathrm{m}$ for version 3 . The beginning of the transformation occurs at $57^{\circ} \mathrm{C}$ and is finished at about $80^{\circ} \mathrm{C}$. The static tests are followed by the dynamic tests, which occur on a test bench shown in Fig. 7.

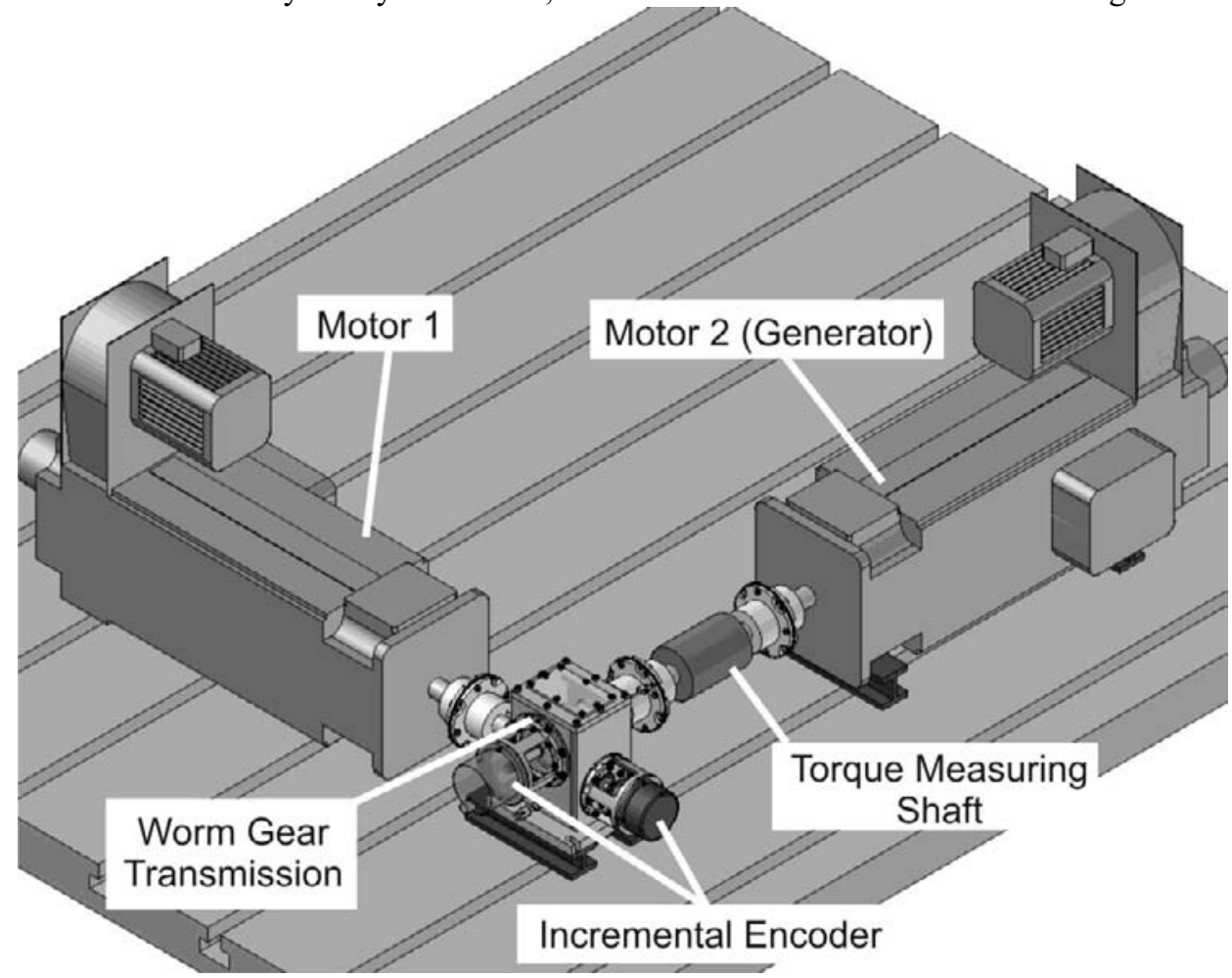

Fig. 7. Test Bench for the dynamic tests of the worm gear transmission

The motor 1 drives the worm gear shaft. The torque is generated by motor 2 and is measured with a torque measuring shaft that is positioned between the worm wheel and the motor 2. The two incremental encoders on the worm shaft and the worm wheel shaft record the change of backlash during the heating and the cooling phase $[3,4]$.

Fig. 7 shows the run for the change of backlash over the SMA-Temperature for a dynamic test using version 2 in accordance to the static tests. After the start of the test the backlash decreases as expected because of the different thermal expansions between housing and the gearwheels. At about $57^{\circ} \mathrm{C}$ the transformation of the NiTi-actuators begins. The backlash increases rapidly until the transformation is finished at about $80^{\circ} \mathrm{C}$. Compared to the beginning of the test, the backlash has increased about $28 \mu \mathrm{m}$. This corresponds to a change of centre distance of $\Delta \mathrm{a}=35 \mu \mathrm{m}$ between the beginning and the end of the test. The run for version 3 is shown in Fig. 9. The adjustment travel of version 3 is lower than the one of the other two versions. Compared with the dynamic test of version 2 shown in Fig. 8 in version 3 the NiTi-actuators compensate the change of backlash caused by the thermal expansions completely. At the operating temperature of $83^{\circ} \mathrm{C}$ the backlash reaches its initial value at the beginning of the test.

The run of the change of backlash during the cooling phase shows Fig. 10 for a test referring to version 2. After stopping the test, the transmission is driven with a low revolution speed and without torque. At first, the temperature of the gearwheels decreases faster than the temperature of the housing. This leads to an increasing backlash. After reaching the Martensite-Start-Temperature, the actuators transform to martensite and their stiffness decreases. The steel springs compress the NiTi-elements and the centre distance decreases as well as the backlash. 


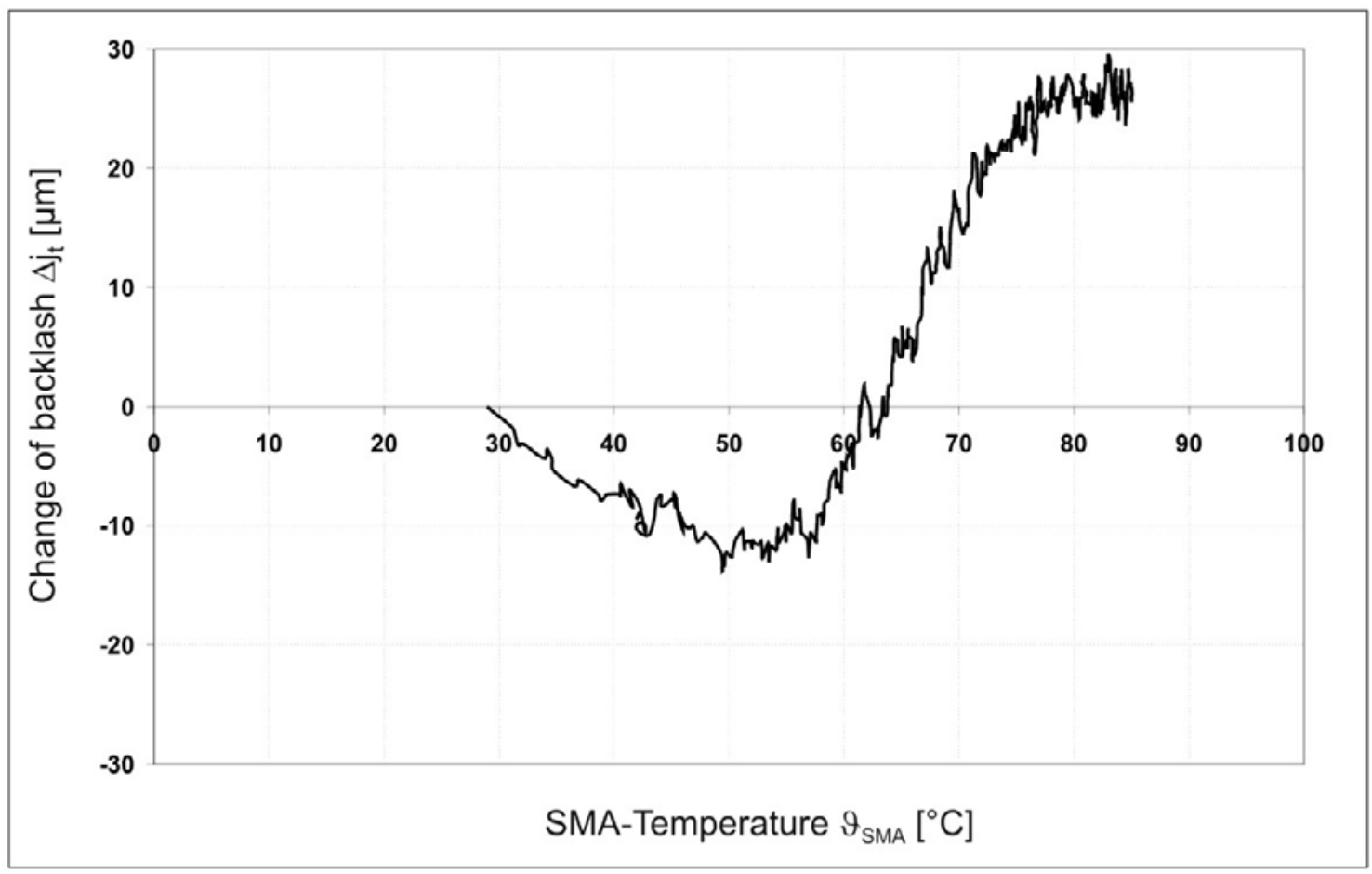

Fig. 8. Change of backlash $\Delta \mathrm{j}_{\mathrm{t}}$ over the SMA-Temperature during the heating phase for version 2

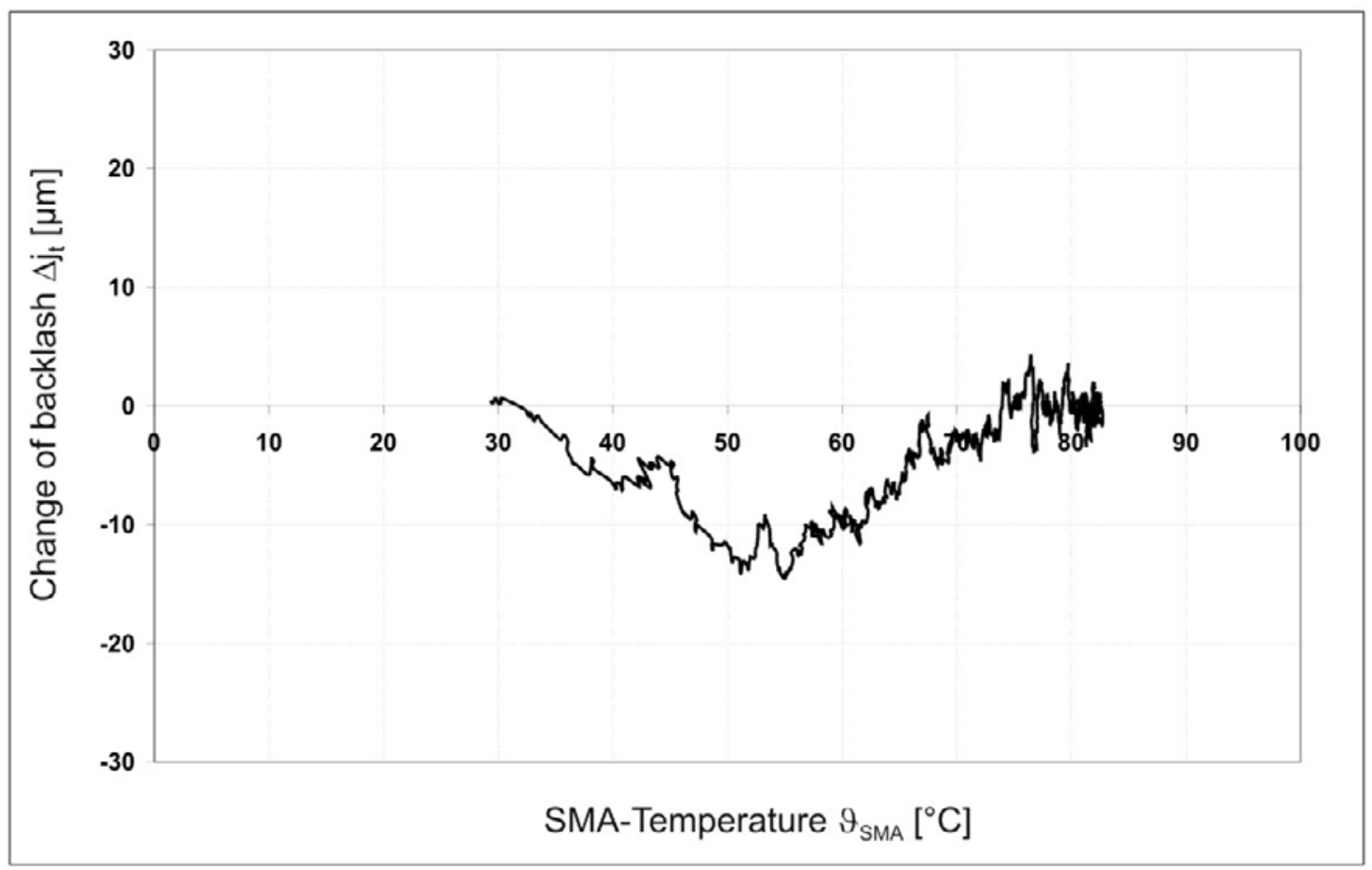

Fig. 9. Change of backlash $\Delta \mathrm{j}_{\mathrm{t}}$ over the SMA-Temperature during the heating phase for version 3 


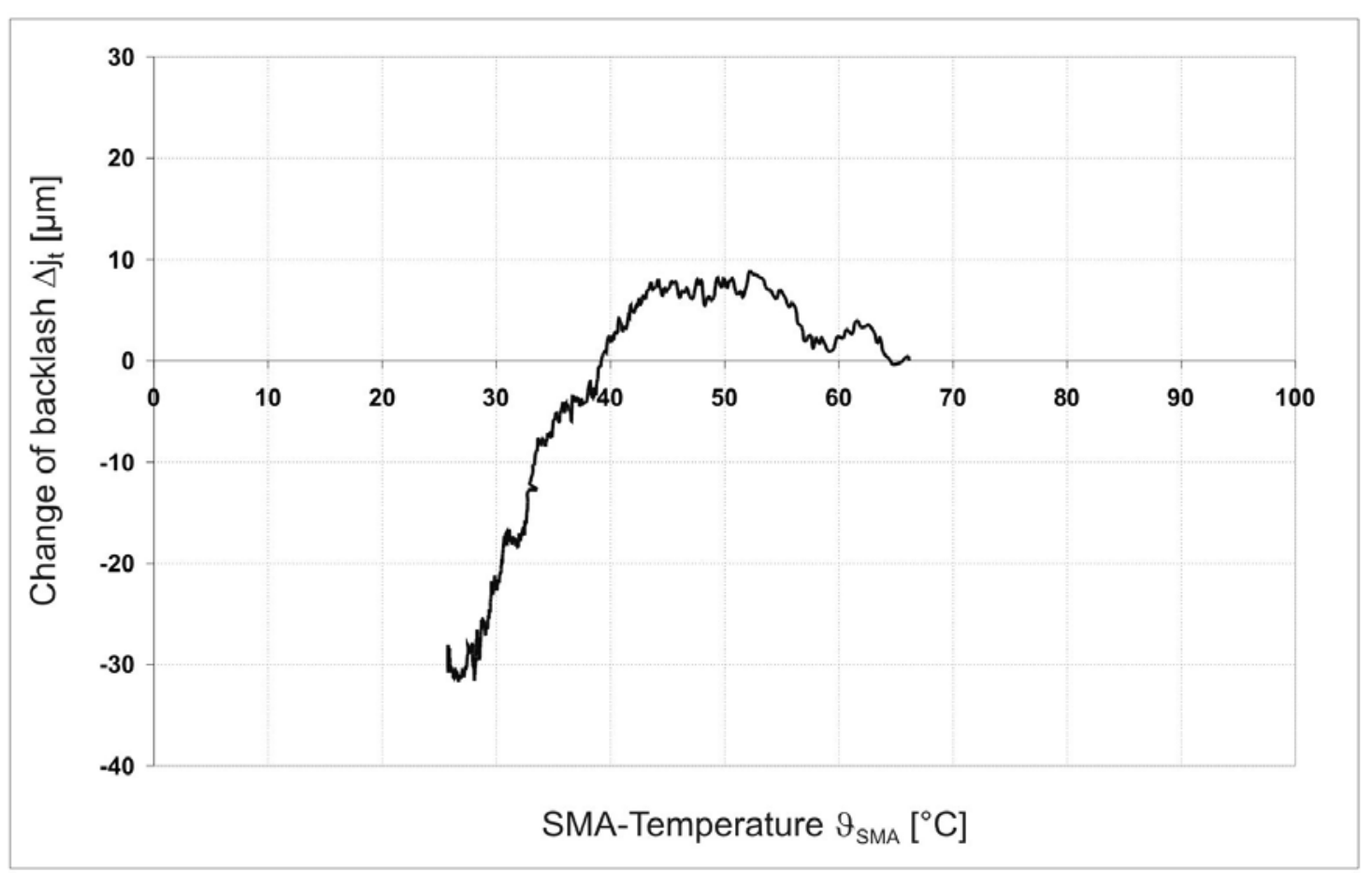

Fig. 10. Change of backlash $\Delta \mathbf{j}_{\mathrm{t}}$ over the SMA-Temperature during the cooling phase for version 2

\section{CONCLUSIONS}

The investigations concerning the use of NiTi-SMA in transmissions to realize low-backlash gearwheels show the high potential of the actuators. Using the extrinsic two-way effect, it is possible to design an independent mechanical system that adjusts the backlash of the transmissions autarkic without an external input. The system is only controlled by the temperature in the transmission. The use of steel disc springs and cylindrical NiTi elements offers the possibilty to realize nearly every adjustment travel and to optimize the actuator system individually for every transmission.

\section{Acknowledgment}

The authors acknowledge funding by the Deutsche Forschungsgemeinschaft (DFG) in the framework of the project B5 of SFB 459 (Sonderforschungsbereich: Formgedächtnistechnik).

\section{References}

[1]T. Waram, in: T.W. Duerig, K.N. Melton, D. Stöckel, CM Wayman (Ed.), Design Principles For NiTi Actuators, Butterworth-Heinemann, London, 1990, 237, 242.

[2]DIN 2093, Disc springs - Quality specifications - Dimensions, DIN Deutsches Institut für Normung e.V., März 2006

[3]Böhmer, Entwicklung eines Standardtests zur Erprobung von Schmier- und Werkstoffen, Dissertation, Bochum, 1991

[4]Jacek, Werkstoff- und Fertigungsoptimierung für Schneckenräder, Dissertation, Bochum, 2001 